\section{Psicologia Escolar \\ e Educacional}

ARTIGO

DOI: http://dx.doi.org/10.1590/2175-35392021223371

Localizador - e223371

\title{
PSICOLOGIA ESCOLAR E EDUCAÇÃO PROFISSIONAL E TECNOLÓGICA NOS IFPIs: DEMANDAS, PRÁTICAS E INDÍCIOS DE CRITICIDADE
}

\author{
Thaisa da Silva Fonseca $^{1} \mathbb{D}$; Fauston Negreiros $^{1}(\mathbb{D}$
}

\section{RESUMO}

Esta pesquisa de campo objetivou analisar as práticas desenvolvidas pelas psicólogas escolares nos Institutos Federais de Educação, Ciência e Tecnologia do Piauí (IFPIs). Participaram do estudo dez psicólogas escolares. Fez-se uso dos pressupostos teóricos e metodológicos da Psicologia Histórico-Cultural. A análise dos dados foi realizada a partir das descrições empírica e teórica, no estabelecimento de unidades de análise e no retorno à realidade dos dados para explicá-los. Os resultados indicaram que as práticas desenvolvidas pelas psicólogas escolares abrangeram ações com foco individual e coletivo junto aos variados atores sociais da instituição e diante dos diversos níveis e/ou modalidades educacionais, sugerindo formas de atuação tradicionais e emergentes. Perceberam-se indícios de criticidade na prática das psicólogas, à medida que se notou movimento de mudança de uma perspectiva clínica para uma perspectiva institucional em Psicologia Escolar, pensando os diferentes segmentos educacionais e o próprio território institucional e suas relações com o contexto político, econômico e cultural.

Palavras-chave: atuação do psicólogo; psicologia escolar; educação profissional.

\section{School Psychology for professional and technological education at the IFPIs: demands, practices, and signs of criticality}

\begin{abstract}
This field research aimed to analyze the practices developed by school psychologists at the Federal Institutes of Education, Science and Technology of Piauí (IFPIs). Ten school psychologists participated in the study. The theoretical and methodological assumptions of Historical-Cultural Psychology were used. The analysis of the data was carried out from the empirical and theoretical descriptions, in the establishment of units of analysis and in the return to the reality of the data to explain them. The results indicated that the practices developed by school psychologists encompassed actions with individual and collective focus with the various social actors of the institution and in view of the different levels and / or educational modalities, suggesting traditional and emerging ways of acting. Evidence of criticality was perceived in the practice of psychologists, as there was a movement towards a change from a clinical perspective to an institutional perspective in School Psychology, considering the different educational segments and the institutional territory itself and its relations with the political, economic and cultural context
\end{abstract}

Keywords: performance of the psychologist; school psychology; professional education.

\section{Psicología Escolar y Educación Profesional y Tecnológica en los IFPIs: demandas, prácticas e indicios de criticidad}

RESUMEN

En esta investigación de campo se tuvo por objetivo analizar las prácticas desarrolladas por las psicólogas escolares en los Institutos Federales de Educación, Ciencia y Tecnología de Piauí (IFPIs). Participaron del estudio diez psicólogas escolares. Se utilizó los presupuestos teóricos y metodológicos de la Psicología Histórico-Cultural. El análisis de los datos sucedió en la realización de descripción empírica y teórica, en el establecimiento de unidades de análisis y en el retorno a la realidad de los datos para explicarlos. Los resultados indicaron que las prácticas desarrolladas por las psicólogas escolares abarcaron acciones con enfoque individual y colectivo junto a los variados actores sociales de la institución y delante de los diversos niveles y/o modalidades educacionales, sugiriendo formas de actuación tradicionales y emergentes. Se percibió indicios de criticidad en la práctica de las psicólogas, a la medida que se notó movimiento de cambio de una perspectiva clínica para una perspectiva institucional en Psicología Escolar, pensando los diferentes segmentos educacionales y el propio territorio institucional y sus relaciones con el contexto político, económico y cultural.

Palabras clave: actuación del psicólogo; psicología escolar; educación profesional.

\footnotetext{
${ }^{1}$ Universidade Federal do Piauí - Parnaíba - Piauí - PI - Brasil; thaisafonseca23@hotmail.com; faustonnegreiros@ufpi.edu.br
} 


\section{INTRODUÇÃO}

A prática do psicólogo escolar e educacional teve início na Educação Básica (Santana, Pereira, \& Rodrigues, 2014). No Brasil, a Psicologia se inseriu na escola através de um modelo clínico, calcado em uma concepção reducionista do fracasso escolar que responsabilizava o aluno e atendia aos anseios da escola de avaliar, corrigir e curar o "aluno-problema" (Oliveira-Menegotto \& Fontoura, 2015). Entretanto, estudos de Maria Helena Souza Patto, como Psicologia e ideologia: uma introdução à psicologia escolar (1987), A produção do fracasso escolar: histórias de submissão e rebeldia (1990), e Introdução à Psicologia Escolar (1981), foram marcos para outros estudos teórico-críticos na área.

As referidas obras trouxeram uma compreensão de multideterminação do fracasso escolar e sinalizaram o início da Psicologia Escolar Crítica ao problematizarem o processo de escolarização, dando ênfase ao contexto e aos múltiplos atores educacionais. Anunciou-se, assim, um novo momento para a área em que o reconhecimento da Psicologia Escolar e Educacional como psicologia instrumental a serviço da ideologia dominante foi passo importante para transformá-la em Psicologia Crítica (Brasil, 2012).

Considera-se que a perspectiva teórica da Psicologia Histórico-Cultural fornece base para práticas que favorecem o psicólogo escolar e educacional como mediador de relações educacionais. Como possibilidades, têm-se o desenvolvimento de ações junto aos professores, aos alunos, às famílias, à gestão e aos demais membros da comunidade escolar, superando as ações remediativas com ênfase no aluno, que reportam ao início da Psicologia Escolar e Educacional (Conselho Federal de Psicologia, 2013; Tanamachi \& Meira, 2003).

A Lei № 11.892, de 29 de dezembro de 2008, criou os Institutos Federais de Educação, Ciência e Tecnologia (IFETs), instituições que ofertam educação superior, básica e profissional, constituindo-se em um espaço educativo que contempla uma diversidade de níveis e/ ou modalidades de ensino (Brasil, 2008). O surgimento dessas instituições educativas, juntamente com o seu processo de interiorização, resultou no aumento de psicólogos atuando nesses locais e, consequentemente, na Educação Profissional e Tecnológica. Como os demais estados brasileiros, o Piauí também vivenciou essa realidade expansionista. Em 2009, o Instituto Federal de Educação, Ciência e Tecnologia do Piauí (IFPI) possuía apenas cinco Campi em funcionamento (IFPI, 2014). Em 2018, já possuía 21 unidades.

No cenário brasileiro, a Educação Profissional foi marcada, inicialmente, por um caráter assistencialista, voltado para as classes sociais desfavorecidas, com vistas ao ensino de um ofício. Dessa forma, a Educação Profissional foi voltada para as classes populares, e a Educação Superior foi voltada para as classes mais favorecidas (Lima, Silva, \& Silva, 2015).

No início do século XXI, a Educação Profissional passou a ocupar nos governos o discurso central de modalidade educacional destinada principalmente aos jovens para a formação e preparação para o ingresso no mercado de trabalho, visando garantir o desenvolvimento e crescimento econômico do país (Lima et al. 2015).

Todavia, a esses jovens deveria ser garantida uma educação que os tornassem sujeitos emancipados e não apenas sujeitos tecnicamente formados para atender às demandas do capitalismo. A Educação Profissional deixou, assim, de ter um viés assistencialista atribuído somente à qualificação profissional e passou a propor uma formação integral dos sujeitos (Lima et al. 2015). Com essa mudança de perspectiva, a atuação do psicólogo no âmbito da Educação Profissional e Tecnológica, materializada principalmente a partir da criação dos IFETs, é considerada primordial e com amplas possibilidades.

São escassas as investigações em teses e dissertações sobre as práticas do psicólogo escolar e educacional na Educação Profissional e Tecnológica e nos IFETs, principalmente enfatizando um contexto regional específico (Fonseca \& Negreiros, 2019). Dessa forma, este estudo objetivou analisar as práticas desenvolvidas pelas psicólogas escolares e educacionais nos IFPIs, à luz da Psicologia Histórico-Cultural.

\section{Delineamento}

\section{MÉTODO}

Esta pesquisa adotou os pressupostos teórico-metodológicos da Psicologia Histórico-Cultural, baseados no método materialista histórico-dialético (Lukács, 1967; Vigotsky, 2000/1934), além de ter sido inspirada no modelo de análise utilizado na tese de doutorado de Asbahr (2011).

O materialismo histórico-dialético considera que "a compreensão dos fenômenos em sua processualidade e totalidade encontra respaldo apenas na dialética entre singularidade-particularidade-universalidade" (Alves, 2010, p.08), no qual a singularidade do fenômeno o revela em sua imediaticidade, a universalidade o revela em sua complexidade, essência e totalidade histórico-social, e a identificação e tensão entre a singularidade e universalidade se manifestam na particularidade (Lukács, 1970).

Dessa forma, a análise partiu da compreensão de singularidade-particularidade-universalidade presente diante do fenômeno das práticas desenvolvidas pelas psicólogas escolares e educacionais nos IFPIs, conforme Figura 01.

\section{Participantes e Contexto da Pesquisa}

Participaram da pesquisa dez psicólogas escolares e educacionais (P1, P2, P3, P4, P5, P6, P7, P8, P9 e P10) que atuavam em nove Campi do IFPI. A Figura 02, a 
seguir, mostra as unidades do IFPI contempladas na pesquisa, a saber: Angical, Cocal, Corrente, Floriano, Oeiras, Parnaíba, Picos, Piripiri e Teresina Zona Sul, distribuídos, dessa forma, nas quatro mesorregiões piauienses (norte piauiense; centro-norte piauiense; sudeste piauiense e sudoeste piauiense).
Procedimentos de Apreensão dos Dados da Pesquisa e Cuidados Éticos

Esta pesquisa contou com autorização institucional do IFPI e com aprovação do Comitê de Ética em Pesquisa da Universidade Federal do Piauí (UFPI), com número de parecer 6.139.948.

Para a apreensão dos dados, foi necessário realizar

Figura 01. Dialética singularidade-particularidade-universalidade do estudo.

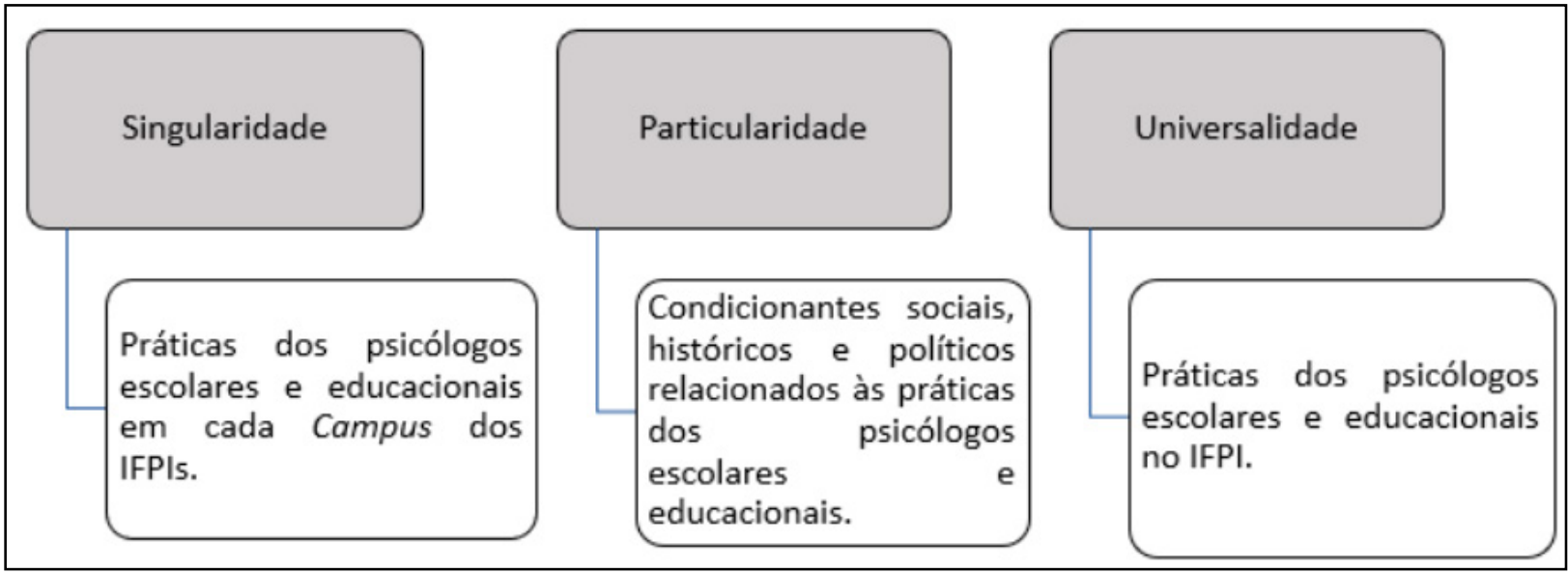

Fonte: Autoria própria (2018), inspirada em estudo de Asbahr (2011).

Figura 02. Unidades dos IFPIs contempladas neste estudo.

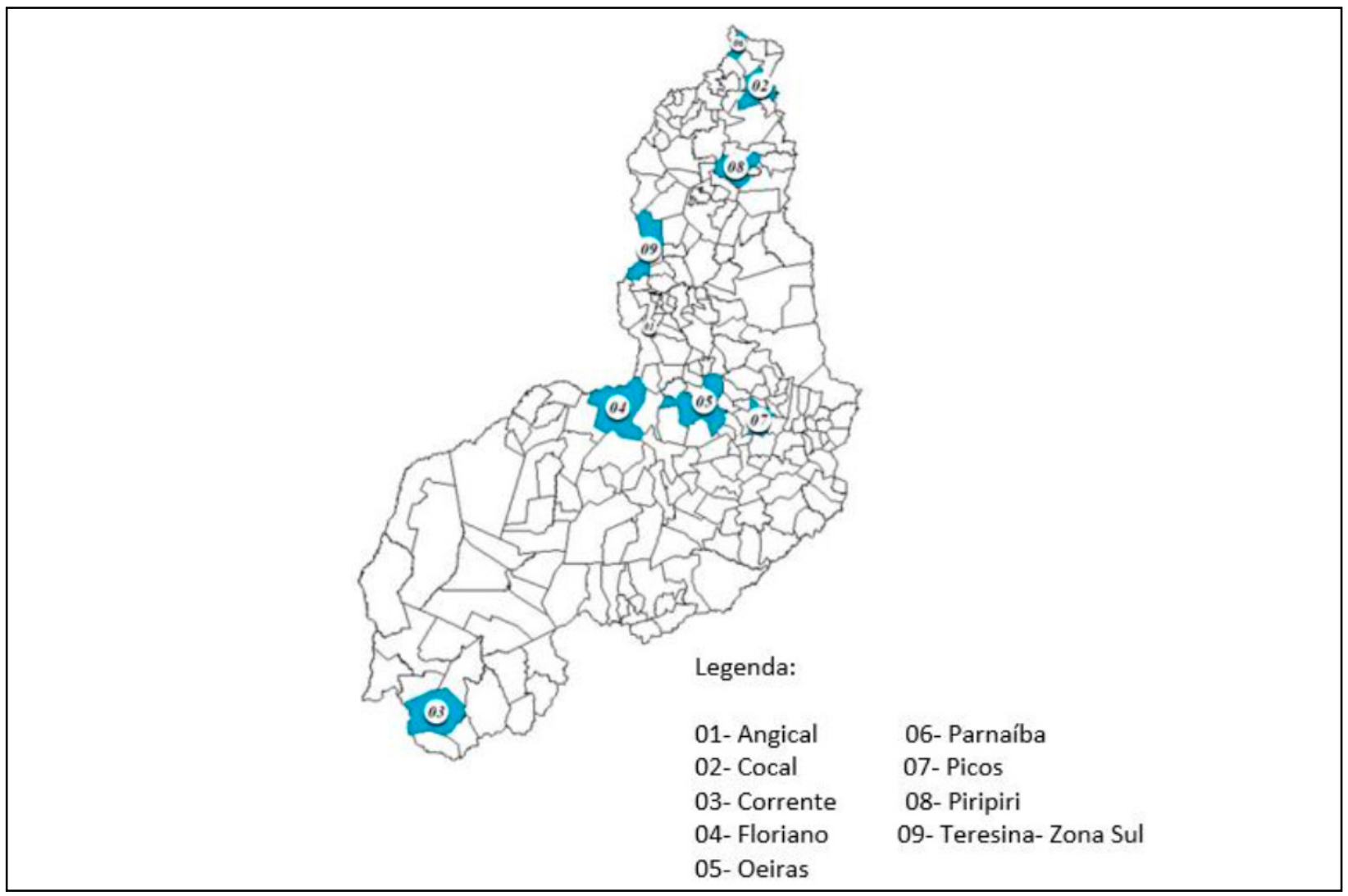

Fonte: Autoria Própria (2018). 
um levantamento do contexto de pesquisa (ver Figura 2), a partir de um roteiro de caracterização institucional e investigação da área de atuação das psicólogas do IFPI e de um questionário de dados sociodemográficos e profissionais. Em seguida, realizaram-se entrevistas semiestruturadas com as psicólogas que atuavam na área da Psicologia Escolar e Educacional nos IFPIs

\section{Procedimentos Analíticos da Pesquisa}

No método da Psicologia Histórico-Cultural, os procedimentos analíticos iniciaram desde a apreensão do real imediato ou da representação inicial e caótica do todo (Lukács, 1967), a partir dos dados coletados, os quais evidenciaram a aparência do fenômeno. Em seguida, realizou-se a descrição empírica, na qual os elementos foram organizados em categorias descritivas que surgiram das temáticas que se apresentaram com maior frequência. Posteriormente, realizou-se a descrição teórica, em que as informações foram organizadas em categorias analíticas ou eixos de análise que surgiram a partir da articulação dos dados empíricos e dos pressupostos teóricos visando à apreensão da essência do fenômeno (Meira, 2014).

Logo então, estabeleceu-se a unidade de análise central do objeto de pesquisa, ou seja, a unidade de análise das práticas desenvolvidas pelas psicólogas escolares e educacionais nos IFPIs (Vigotsky, 2000/1934). Por fim, retornou-se à realidade dos dados para explicá-la, mediado pelas abstrações e a partir dos eixos de análise estabelecidos na descrição teórica, superando a descrição (Lukács, 1967), em um movimento de singularidade - particularidade - universalidade (Lukács, 1970). Esse retorno à realidade dos dados ocorreu a partir da busca pelos indícios de criticidade revelados nas práticas desenvolvidas pelas psicólogas escolares e educacionais.

\section{RESULTADOS E DISCUSSÃO}

A partir das entrevistas, os resultados em torno das práticas em Psicologia Escolar e Educacional possibilitaram a obtenção de oito eixos de análise: Demandas Educacionais; Público-Alvo; Níveis/Modalidades de Ensino; Ações Desenvolvidas; Diretrizes para a Atuação do Psicólogo; Políticas Educacionais; Fragilidade da Rede de Apoio Interdisciplinar e Intersetorial; e, por fim, Indícios de Criticidade na Prática das Psicólogas Escolares e Educacionais nos IFPIs.

\section{Demandas Educacionais}

As psicólogas escolares e educacionais ${ }^{1}$ indicaram como principais demandas educacionais em sua atuação profissional nos IFPIs a orientação para o estudo (P1,

\footnotetext{
${ }^{1}$ Todos os participantes da pesquisa foram mulheres. Dessa forma, optou-se pela utilização da expressão no gênero feminino no decorrer de todo o artigo.
}

P2, P3, P4, P5, P6, P7, P8, P9 e P10), as dificuldades de aprendizagem (P1, P4, P6, P7, P8 e P10), o relacionamento interpessoal (P1, P2, P3, P6 e P8), as questões familiares (P1, P2, P4, P7 e P10), a educação inclusiva (P1, P3, P6 e P10), o bullying (P4, P6, P8 e P10), a adaptação à realidade dos IFPIs (P2, P7 e P9), a saúde mental (P5, P6 e P10), a orientação profissional (P1 e $P 4)$, a automutilação (P7 e P10) e a indisciplina (P4 e P5).

Essas demandas identificadas como resultados desta pesquisa centram-se em aspectos de aprendizagem ou comportamentais dos alunos, semelhantes aos resultados obtidos em pesquisa sobre concepções e práticas de psicólogos escolares e educacionais de João Pessoa relacionadas às queixas escolares, realizada por Cavalcante e Aquino (2013).

\section{Público-Alvo}

Todas as psicólogas escolares e educacionais apontaram mais de um público-alvo de sua atuação profissional, sendo: alunos, professores e família (P2, P6, P8, P9 e P10); alunos, professores, família e servidores (P1, P3, $\mathrm{P} 4$ e $\mathrm{P} 5$ ); e alunos, professores e servidores (P7), como expresso na Figura 03:

Dessa forma, todas as participantes da pesquisa (P1, P2, P3, P4, P5, P6, P7, P8, P9 e P10) indicaram os alunos e os professores como público-alvo de sua atuação profissional nos IFPIs. Juntamente, a maioria também incluiu a família (P1, P2, P3, P4, P5, P6, P8, P9 e P10) e metade (P1, P3, P4, P5 e P7) incluiu servidores e/ou gestão.

Como em outros estudos que possuíram como objeto de estudo a atuação do psicólogo escolar e educacional (Yamamoto, Santos, Galafassi, Pasqualini \& Souza, 2013), o público-alvo da prática desse profissional abrangeu diversos atores escolares. Esse dado é relevante na medida em que sugere indícios de criticidade no exercício profissional no ambiente educacional ao envolver toda a comunidade escolar como preconizam as pesquisas e/ou documentos norteadores (CFP, 2013).

\section{Níveis/Modalidades de Ensino}

Todas as psicólogas escolares e educacionais indicaram desenvolver práticas junto a mais de um nível e/ou modalidade de ensino nos IFPIs, sendo: Ensino Técnico Integrado ao Médio, Ensino Técnico Concomitante/ Subsequente ao Médio e Ensino Superior (P2, P4, P5, P6, P7, P8, P9, P10); Ensino Técnico Integrado ao Médio, Ensino Superior, Educação de Jovens e Adultos (EJA) e Programa Nacional de Acesso ao Ensino Técnico e Emprego (PRONATEC) (P1); Ensino Técnico Integrado ao Médio, Ensino Técnico Concomitante/Subsequente, Ensino Superior e EJA (P3), como ilustrado na Figura 04.

Dessa forma, todas as participantes da pesquisa (P1, P2, P3, P4, P5, P6, P7, P8, P9 e P10) desenvolveram práticas junto ao Ensino Técnico Integrado ao Médio e 
Figura 03. Porcentagem do público-alvo da prática das psicólogas escolares e educacionais nos IFPIs.

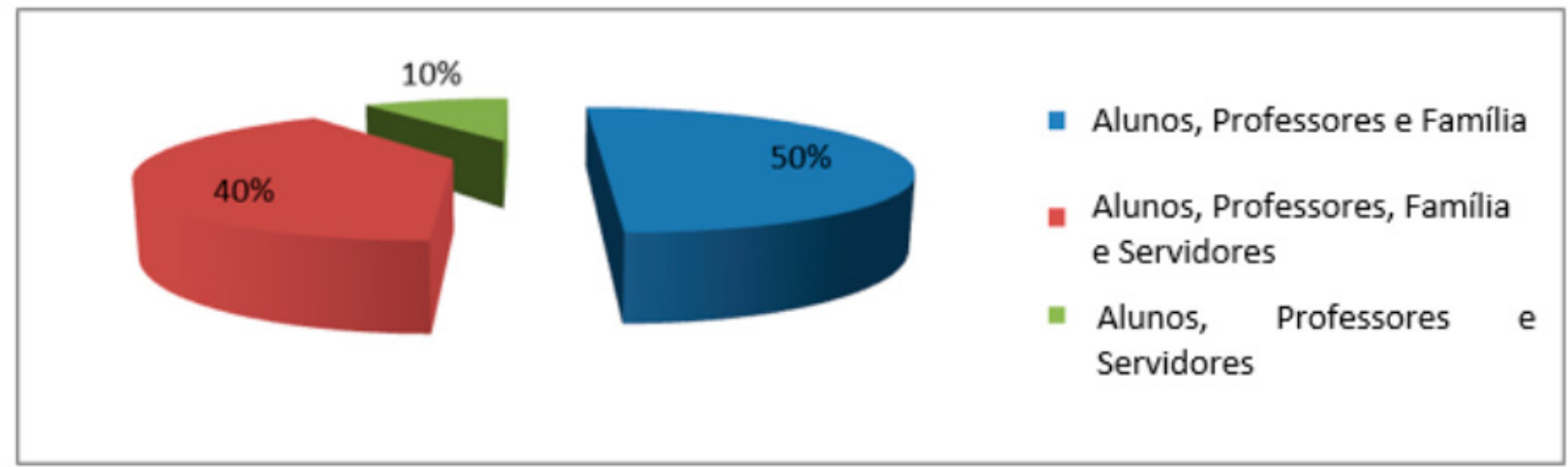

Fonte: Roteiro de entrevista semiestruturada. Autoria própria (2018).

ao Ensino Superior. A maioria (P2, P3, P4, P5, P6, P7, P8, P9 e P10) também desenvolveu ações junto ao Ensino Técnico Concomitante/Subsequente ao Médio. Duas participantes (P1 e P3) incluíram EJA e uma participante (P1) incluiu PRONATEC.

Todas as psicólogas escolares e educacionais dessa pesquisa revelaram atuar junto ao Ensino Técnico Integrado ao Médio, dado semelhante ao encontrado nos estudos sobre a atuação do psicólogo nos IFETs (David, 2017; Ferro, 2017), que indicaram foco de atuação junto a esse nível e/ou modalidade de ensino. No entanto, os resultados foram diferentes na medida em que nos IFPIs se verificou uma atuação mais ampla, envolvendo não somente um nível e/ou modalidade de ensino.

Vale mencionar ainda que as ações desenvolvidas junto ao Ensino Técnico Integrado ao Médio são mais sistemáticas quando comparadas às ações desenvolvidas junto aos demais níveis e/ou modalidades de ensino, as quais são esporádicas, pontuais e mediante demandas espontâneas. Além disso, é importante considerar que todas as participantes indicaram atuar junto à metade
(P5, P6, P7 e P8) e/ou à maioria (P1, P2, P3, P4, P9 e P10) dos níveis ou modalidades ofertadas em seus Campi, o que é relevante considerando que os Institutos Federais se caracterizam pela oferta da educação superior, básica e profissional (Brasil, 2008).

Desse modo, a prática dessas psicólogas escolares e educacionais mostrou-se significativa na medida em que procurou atender a públicos e demandas diversas, apesar de seus Campi contarem, em sua maioria, com apenas uma psicóloga.

\section{Ações Desenvolvidas}

Em relação às ações desenvolvidas pelas psicólogas escolares e educacionais junto aos alunos, todas indicaram realizar atendimento individualizado direcionado a orientações e/ou aconselhamento; projetos coletivos em formato de palestras, oficinas e/ou cines debates direcionados a temas diversos como bullying, orientação profissional etc.; e orientação para o estudo (P1, P2, P3, P4, P5, P6, P7, P8, P9 e P10).

Além disso, mencionaram realizar seleção e acompa-

Figura 04. Porcentagem dos níveis/modalidades de ensino contemplados na prática das psicólogas escolares e educacionais nos IFPIs.

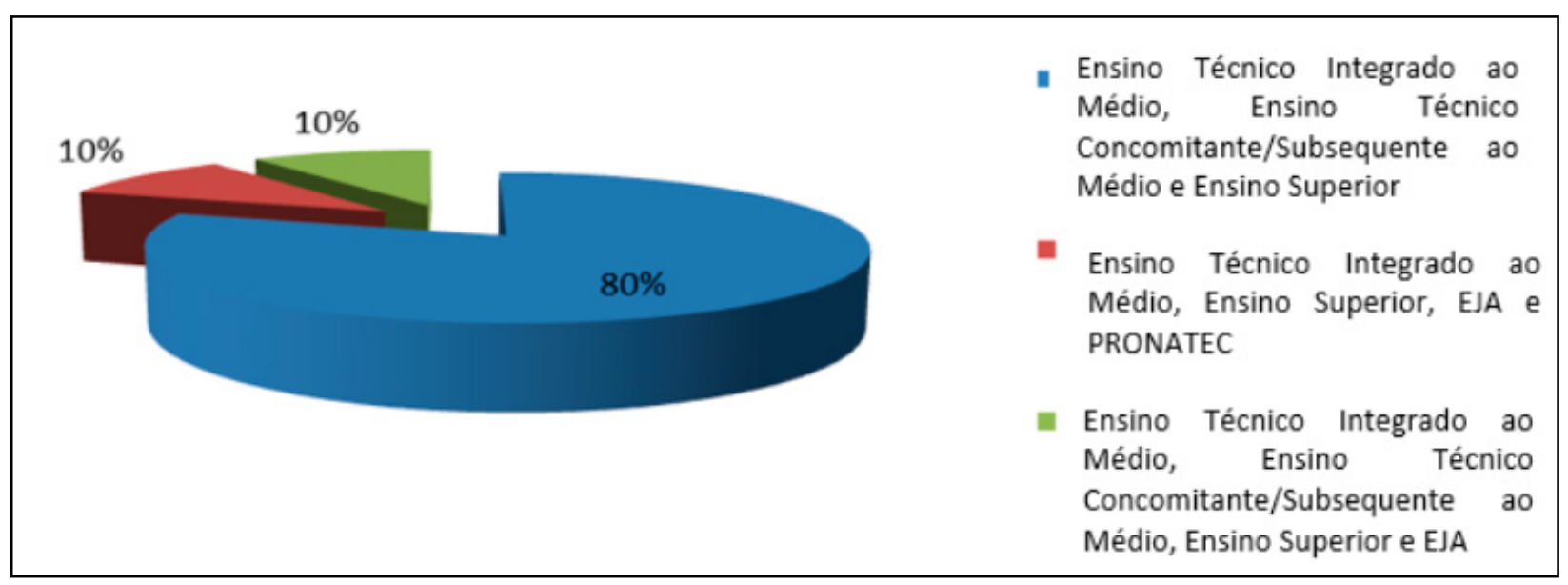

Fonte: Roteiro de entrevista semiestruturada. Autoria própria (2018). 
nhamento de alunos bolsistas da Política de Assistência Estudantil (POLAE), inclusive através de visitas domiciliares (P1, P4, P6, P7, P9 e P10); acolhimento de novos alunos do Ensino Técnico Integrado ao Médio através do Programa de Acolhimento ao Estudante Ingressante (PRAEI) ou do Ensino Superior por meio de projeto em conjunto com as Coordenações de alguns cursos (P4, P5, P7 e P10); pesquisas educacionais sobre perfil do estudante e estilos de aprendizagem para embasar demais ações (P3, P8 e P9); atividade coletiva em sala de aula frente a demandas espontâneas (P1, P2 e P6); orientação profissional (P1 e P4) e mediação de conflitos (P2).

No que concerne às ações desenvolvidas junto aos professores, tiveram: participação em momentos de discussão pedagógica, como Conselhos de Classe, reuniões de professores (P1, P2, P3, P4, P5, P6, P9 e P10); palestras nos encontros pedagógicos (P1, P2, P3, P5, P9 e P10); orientações aos professores (P4, P6, P7, P8 e P10) e projetos coletivos (P3 e P9). As ações desenvolvidas junto à família incluíram palestras nas reuniões de pais e atendimento individualizado direcionado a orientações (P1, P2, P5, P6, P9 e P10).

Por fim, as psicólogas escolares e educacionais indicaram realizar junto aos servidores palestras e atividades pontuais coletivas de socialização de novos servidores (P1, P3, P4 e P5) e atendimento individualizado a servidores (P1) mediante demanda espontânea.

Verificou-se, dessa forma, uma maior diversidade de ações desenvolvidas junto aos alunos, seguida pelas desenvolvidas com professores e, por fim, tendo como público famílias e servidores, de maneira equivalente. Os projetos, em específico, foram desenvolvidos somente com alunos e com professores.

Todas as psicólogas escolares e educacionais relataram desenvolver projetos que tinham os alunos como público e que englobavam temáticas como bullying, sexualidade, inteligência emocional, habilidades sociais, valorização à vida, etc. (P2, P3, P4, P6, P7, P8, P9 e P10); orientação profissional (P1, P4, P5, P7 e P10); educação em saúde, como janeiro branco, setembro amarelo, etc. (P1, P4 e P6); acompanhamento e orientação a alunos repetentes ( $P 1$ e $P 5)$; formação para líderes de turma (P4 e P8) e arte e formação humana (P3). Duas participantes relataram desenvolver projeto com professores direcionado à discussão de temas como adaptação curricular, educação inclusiva, etc. (P3 e P9).

Essas informações se assemelharam às obtidas em pesquisa na qual a maioria dos projetos desenvolvidos foi direcionada aos alunos e teve temas relacionados ao público infanto-juvenil (Yamamoto et al., 2013). As práticas elencadas anteriormente sugeriram, concomitantemente, ações tanto com foco individual como com foco coletivo junto aos variados público-alvo da atuação do psicólogo: alunos, professores, família e/ ou servidores.
Dessa forma, coexistiram formas de atuação tradicionais (atendimento individualizado, orientação para o estudo, atividade coletiva em sala de aula frente a demandas, orientação profissional, mediação de conflitos, orientação aos professores, palestras pontuais nos Encontros Pedagógicos, nas reuniões de pais e/ou para os servidores) e emergentes (projetos coletivos, seleção e acompanhamento de alunos bolsistas da POLAE, acolhimento a alunos novatos, pesquisas educacionais, participação em momentos de discussão pedagógica) por parte das psicólogas escolares e educacionais participantes da pesquisa (Martínez, 2009).

Percebeu-se ainda que as práticas se assemelharam às preconizadas pelos órgãos norteadores da profissão (CFP, 2013), sendo relevante destacar a atuação junto a políticas públicas educacionais, cuja ação do psicólogo escolar e educacional nesse âmbito deve ser considerada expressão do compromisso com os processos educativos (Martínez, 2009; Souza, 2010).

Em suma, dentre as principais práticas no âmbito da Psicologia Escolar e Educacional indicadas nesta pesquisa percebeu-se que formas de atuação emergentes começaram a ganhar notoriedade nos IFETs, espaços que se encontram em processo de construção e consolidação de suas práticas (Jorge, 2017; Martínez, 2009).

Além disso, verificou-se o envolvimento dos diversos atores educacionais nas práticas desenvolvidas (CFP, 2013; Tanamachi \& Meira, 2003), buscando superar o modelo clínico-médico estabelecido historicamente (Barbosa, 2012; Oliveira-Menegotto \& Fontoura, 2015) e alcançar um modelo de atuação institucional, em uma perspectiva crítica em Psicologia Escolar e Educacional (Barbosa, 2012; Campos, 2010; Oliveira-Menegotto \& Fontoura, 2015).

Acrescenta-se também que, semelhante ao que estudos apontam sobre a atuação do psicólogo no Ensino Superior, verificou-se uma atuação caracterizada pela revisão de práticas consolidadas historicamente e pela inserção de novas práticas (Santos, Souto, Silveira, Perron \& Dias, 2015) direcionadas para a coletividade e que trabalham as relações presentes no ambiente educacional, com foco nas políticas educacionais e nos demais fatores envolvidos no processo de ensino e aprendizagem (Jorge, 2017), o que sugere um viés crítico nessas práticas.

Dessa forma, corrobora-se a necessidade de atuação do psicólogo escolar e educacional junto a novos contextos educativos (Barbosa, 2012), como o contexto da Educação Profissional e Tecnológica, para que as práticas desenvolvidas no âmbito da Psicologia Escolar e Educacional nesses locais sejam fortalecidas, contextualizadas e efetivas.

\section{Diretrizes para a Atuação do Psicólogo}

Um aspecto importante referente à prática do psicó- 
logo escolar e educacional referiu-se às diretrizes para a atuação do psicólogo nos IFPIs. Todas as psicólogas escolares e educacionais mencionaram a descrição de cargos contida no Ofício Circular no 015/2005/CGGP/SAA/SE/ MEC (Brasil, 2005), porém enfatizaram a dificuldade em orientar as suas práticas a partir desse documento ( $P 1$, P2, P3, P4, P5, P6, P7, P8, P9 e P10).

$O$ referido documento é generalista e abrange diversas áreas da Psicologia, o que termina por refletir na identidade do psicólogo, como também indicado por Sommer e Bordas (2018) em relato referente às práticas dos psicólogos no Instituto Federal de Educação Profissional e Tecnológica da Bahia (IFBA). Esses autores refletem que os psicólogos podem ficar desconexos em sua identidade profissional devido à quantidade de atribuições requeridas a esses profissionais.

Diante disso, três psicólogas mencionaram orientarem-se pelas atribuições do psicólogo previstas na POLAE (P1, P2 e P5) e seis mencionaram um movimento do grupo de psicólogos dos IFPIs em defenderem o desenvolvimento de práticas em Psicologia Escolar e Educacional nos Institutos (P1, P4, P6, P7, P9 e P10), o que revelou um importante posicionamento político.

\section{Políticas Educacionais}

As psicólogas escolares e educacionais relataram estarem inclusas nas Políticas de Assistência Estudantil (P1, P2, P4, P5, P6, P7, P8, P9 e P10) e de Inclusão (P2, P3, P4, P5, P6, P7 e P10). Dessa forma, existem psicólogas tanto atuando em apenas uma (P1, P3, P8 e P9) quanto em ambas as políticas (P2, P4, P5, P6, P7 e P10), conforme indicado na Figura 05.

A prática em políticas educacionais vem sendo discutida como relevante eixo e forma de atuação emergente do psicólogo, sendo essencial a sua participação não somente na efetivação como também na discussão e na elaboração de políticas públicas (Martínez, 2009; Souza, 2010). Assim, destaca-se a importância de que as psicólogas escolares e educacionais nos IFPIs desenvolvam práticas e contribuam para a efetivação das políticas de Assistência Estudantil e de Inclusão.

\section{Fragilidade da Rede de Apoio Interdisciplinar e Intersetorial}

A maioria das participantes (P1, P2, P4, P6, P9 e P10) revelou a fragilidade da rede de apoio interdisciplinar e intersetorial dos municípios em que atuam, o que refletiu na necessidade de realização de acompanhamento individualizado no contexto dos IFPIs frente a alunos em situações de risco, como exemplificado nos relatos a seguir:

[...] de ter uma expectativa de que a gente faça atendimento clínico mesmo, terapia, principalmente no interior que não tem tanto psicólogo assim, que tem uma demanda grande de pessoas pra rede pública e a Psicologia ainda é deficitária né [...] P1.

[...] tem muita demanda de saúde mental, às vezes eu até tento fugir um pouco disso, mas acaba ficando difícil, como o nosso público é geralmente muito carente e não tem plano de saúde, às vezes eles demoram pra conseguir um acompanhamento fora, e às vezes é um caso que tem ideação suicida ou tentativa e aí isso acaba tomando muito meu tempo, então a gente tem que tá dando esse suporte [...] P6.

[...] a gente pega algumas demandas de suicídio, é uma demanda muito forte aqui na cidade [...] não tem como a gente não entrar um pouquinho na clínica também, principalmente a gente que trabalha no interior, a gente vai encaminhar um aluno que está com risco de suicídio pro CAPS e o profissional demora muito a atender, então é toda uma dificuldade. $P 9$.

[...] já aconteceram casos de eu fazer acompanhamentos que são mais voltados pra psicoterapia mesmo por uma questão de fragilidade da rede, o aluno tinha ideações suicidas e eu fiquei muito preocupada mesmo de ele não conseguir na rede e ficar sem acompanhamento e eu está negligenciando [...] P10.

De maneira descontextualizada, os relatos anteriores

Figura 05. Porcentagem das políticas públicas contempladas na prática das psicólogas escolares e educacionais nos IFPIs.

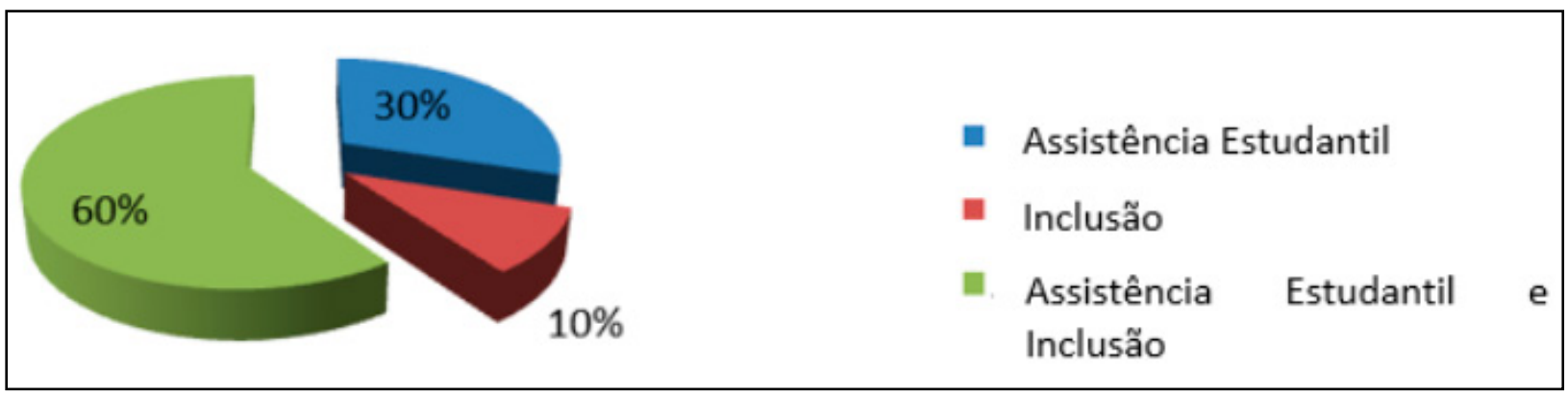

Fonte: Roteiro de entrevista semiestruturada. Autoria própria (2018). 
poderiam ser criticados por terem indicado um viés clínico de atuação em Psicologia Escolar e Educacional, na medida em que sugeriram um acompanhamento individualizado semelhante à psicoterapia realizado junto ao aluno, em ambiente escolar. No entanto, partindo da compreensão singularidade-particularidade-universalidade do estudo e considerando todo o contexto social, histórico, cultural e educativo, as psicólogas escolares e educacionais revelaram um olhar de cuidado amplo, integral e crítico com os indivíduos público-alvo de sua atuação. Assinala-se ainda que esse acompanhamento era conjugado com outras ações de apoio ao estudante, mediante intervenções junto a atores sociais cuidadores dos discentes (familiares, professores, equipe gestora).

Além disso, as psicólogas estavam cumprindo os princípios éticos da profissão, conforme os segundo e terceiro princípios fundamentais que afirmam, respectivamente, que o psicólogo "trabalhará visando promover a saúde e a qualidade de vida das pessoas e das coletividades e contribuirá para a eliminação de quaisquer formas de negligência, discriminação, exploração, violência, crueldade e opressão" (Conselho federal de Psicologia, 2005, p. 07) e "atuará com responsabilidade social, analisando crítica e historicamente a realidade política, econômica, social e cultural" (CFP, 2005, p. 07). As falas retrataram também um compromisso ético-político (Patto, 1987) com a profissão.

\section{Indícios de Criticidade na Prática das Psicólogas Escolares e Educacionais nos IFPIs}

Autores como Meira (1997), Patto (1987), Souza (2010; 2017), Tanamachi (1997) e Tanamachi e Meira (2003) realizaram estudos nos quais elencaram indícios de embasamento crítico em Psicologia Escolar e Educacional, norteados pela atuação desse profissional junto aos diversos atores escolares.

Nesta pesquisa também foi possível localizar indícios de criticidade nas práticas desenvolvidas pelas psicólogas escolares e educacionais dos IFPIs, como a compreensão da importância do distanciamento da perspectiva clínica de atuação do psicólogo nos IFPIs (P6, P8 e P10) e de que não é possível fazer clínica na escola (P3), o que revelou o questionamento de práticas clínico-terapêuticas que desconsideram os demais determinantes do processo de escolarização (Meira, 1997; Patto, 1987; Souza, 2017).

Além disso, a contribuição do psicólogo escolar e educacional com o processo de ensino e aprendizagem (P1, P6, P7, P8 e P10), o posicionamento político de seguir a atuação em Psicologia Escolar e Educacional nos IFPIs (P1, P4, P6, P7, P9 e P10) e a solicitação de mudança de setor de lotação nos IFPIs (P4) revelaram o compromisso da Psicologia com a questão educacional (Meira, 1997; Patto, 1987; Souza, 2010; Tanamachi, 1997).
Outros indícios de criticidade foram as compreensões de Psicologia Escolar e Educacional e de desenvolvimento humano baseadas em uma concepção global de homem (P1, P5, P6, P7 e P9), pois revelaram o embasamento nessa concepção, como indicado por Tanamachi (1997) e Patto (1987).

O desenvolvimento de projetos junto aos alunos ( $P 1$, P2, P3, P4, P5, P6, P7, P8, P9 e P10) e aos professores (P3 e P9); de palestras nas reuniões de pais ( $P 1, P 2$, $\mathrm{P5}, \mathrm{P} 6, \mathrm{P} 9$ e $\mathrm{P} 10)$ e nos encontros pedagógicos (P1, P2, P3, P5, P9 e P10); e a participação em momentos de discussão pedagógica (P1, P2, P3, P4, P5, P6, P9 e P10) revelaram a existência de espaços reflexivos no interior da escola, inclusive sobre a prática pedagógica (Meira, 1997; Souza, 2010), além da construção de relações que permitiram o máximo desenvolvimento possível do homem (Tanamachi \& Meira, 2003).

A atuação junto às políticas educacionais de Assistência Estudantil (P1, P2, P4, P5, P6, P7, P8, P9 e P10) e de Inclusão (P2, P3, P4, P5, P6, P7 e P10), revelou a contribuição das psicólogas escolares e educacionais na implantação de políticas públicas (Souza, 2010).

Os projetos coletivos junto aos professores ( $\mathrm{P3}$ e $\mathrm{P9})$ e as palestras nos encontros pedagógicos (P1, P2, P3, P5, P9 e P10) revelaram a atuação das psicólogas escolares e educacionais na formação docente (Souza, 2010). Juntamente a isso, a parceria de professores para viabilizar a realização de projetos junto aos alunos (P2, P3 e P7) e a parceria de outros profissionais dos IFPIs para o desenvolvimento de ações de educação em saúde (P1, P4 e P6) revelaram a realização de um trabalho interdisciplinar e multiprofissional (Souza, 2010).

$O$ desenvolvimento de projeto para a formação de líderes de turma (P4 e P8) revelou uma ação que permitiu o aumento da participação popular na escola (Tanamachi \& Meira, 2003). A realização de pesquisas educacionais, como referentes ao perfil do estudante e aos estilos de aprendizagem (P3, P8 e P9) revelou a consideração dos interesses e da realidade dos alunos para o planejamento das ações educacionais (Tanamachi \& Meira, 2003).

A formação continuada também direcionada para a área educacional, seja em nível de pós-graduações Lato Sensu ou Stricto Sensu, seja em nível de cursos complementares (P1, P3, P5, P7, P8 e P9) revelou uma busca por reflexões teóricas para embasar as ações (Meira, 1997).

Além disso, a concepção das psicólogas sobre a importância da Psicologia Escolar e Educacional nos IFETs e, de maneira específica, nos IFPIs para a educação pública (P1, P2 e P10); e a necessidade de se reinventar diante dos desafios profissionais, como através de um coletivo de discussão de práticas nos IFPIs (P1, P2, P3, P4, P5, P6, P7, P8, P9 e P10) também são indícios de criticidades relevantes. Dessa forma, assumir uma postura crítica é o caminho para transformar o atual cenário das instituições educacionais. 


\section{SÍNTESE INTEGRADORA}

Esta pesquisa, fundamentada nos pressupostos da Psicologia Histórico-Cultural, objetivou analisar as práticas desenvolvidas pelas psicólogas escolares e educacionais nos IFPIs.

Os resultados obtidos indicaram ações com foco individual e coletivo junto aos variados públicos de atuação da instituição de ensino, sugerindo formas de atuação tradicionais e emergentes. Estas últimas se destacaram por seu caráter inovador diante da defesa pela atuação em Psicologia Escolar e Educacional, principalmente diante do ingresso mediante um concurso público que possui uma descrição de cargo que possibilita diversos perfis de atuação junto à instituição.

Perceberam-se indícios de criticidade na prática das psicólogas à medida que se notou movimento de mudança de uma perspectiva clínica para uma perspectiva institucional em Psicologia Escolar, pensando os diferentes segmentos educacionais e o próprio território institucional e suas relações com o contexto político, econômico e cultural.

O recorte geográfico longilíneo do estado foi o principal percalço encontrado no decorrer desta pesquisa e também é um dos desafios que essas profissionais encontram em suas práticas, pois tende a centralizar serviços especializados e de formação junto à capital. No entanto, de maneira estratégica e inovadora, elas edificaram o que pode ser denominado de coletivo para discutir as práticas e potencializar o espaço educativo.

Frente a esse panorama, a realização desta investigação científica contribuiu para suprir a lacuna existente em torno da temática da atuação do psicólogo na Educação Profissional e Tecnológica nos IFPIs. Além disso, também evidenciou a relevância de estudos abrangendo novas modalidades e contextos educacionais, principalmente em âmbito regional, na medida em que favorece a reflexão sobre a necessidade de que as práticas desenvolvidas sejam contextualizadas e que reafirma que a aprendizagem em ambiente formal de ensino também promove o desenvolvimento e a transformação do sujeito.

Conclui-se que a participação de psicólogos escolares e educacionais nas políticas educacionais, aliando a sua operacionalização com os pontos de criticidade é um caminho valioso para inserção desses profissionais em instituições públicas de ensino. De maneira semelhante, a formação de coletivos de profissionais da Psicologia Escolar e Educacional é fundamental para o fortalecimento de práticas em contextos emergentes de atuação em Psicologia Escolar.

\section{REFERÊNCIAS}

Alves, A. M. (2010). O método materialista histórico dialético: alguns apontamentos sobre a subjetividade. Revista de Psicologia da UNESP, 9 (1), 1-13.

Asbahr, F. S. F. (2011). "Por que aprender isso, professora?"
Sentido pessoal e atividade de estudo na Psicologia histórico-cultural (Tese de Doutorado). Universidade de São Paulo, São Paulo, SP, Brasil.

Barbosa, D. R. (2012). Contribuições para a Construção da Historiografia da Psicologia Educacional e Escolar no Brasil. Psicologia: Ciência e Profissão, 32 (no. spe), 104-123. doi: 10.1590/S1414-98932012000500008

Brasil, Ofício Circular no 015/2005/CGGP/SAA/SE/MEC. (2005). Plano De Carreira Dos Cargos Técnico-Administrativos Em Educação - Descrição Do Cargo. Brasília, DF: Ministério da Educação.

Brasil, Lei no 11.892. (2008). Institui a Rede Federal de Educação Profissional, Científica e Tecnológica, cria os Institutos Federais de Educação, Ciência e Tecnologia, e dá outras providências. Brasília, DF.

Brasil, R. T. (2012). Psicologia Escolar: o desafio da crítica em tempos de cinismo. Psicologia Escolar e Educacional, 16(2), 209-217. doi: 0.1590/S1413-85572012000200004

Campos, H. R. F. (2010). Reflexões sobre a evolução e tendências contemporâneas na historiografia da psicologia educacional no Brasil. In Yamamoto, O. H. \& Costa, A. L. F. (Eds.), Escritos sobre a profissão de psicólogo no Brasil (pp.215-227). Natal: EDUFRN.

Cavalcante, L. A.; Aquino, F. S. B. (2013). Ações de psicólogos escolares de João Pessoa sobre queixas escolares. Psicologia em Estudo, 18 (2), 353-362. doi:10.1590/S141373722013000200016

Conselho Federal de Psicologia (2005). Código de Ética Profissional do Psicólogo. Brasília: CFP.

Conselho Federal de Psicologia. (2013). Referências Técnicas para Atuação de Psicólogas (os)na Educação Básica. Brasília: CFP.

David, M. M. (2017). Atuação da psicologia escolar no Instituto Federal de Goiás: concepções epráticasDissertação de Mestrado). Universidade de Brasília, Brasília, DF, Brasil.

Ferro, A. S. (2017). Tornar-se psicólogo escolar: a formação da identidade profissional no Instituto Federal de Educação de Goiás (Dissertação de Mestrado). Universidade de Brasília, Brasília, DF, Brasil.

Fonseca, T. S.; Negreiros, F. (2019). Estado da arte da atuação do psicólogo escolar no âmbito da Educação Profissional e Tecnológica. In Negreiros, F.; Souza, M. P. R. (Eds.), Práticas em psicologia escolar: do ensino técnico ao superior (Vol. 9, pp. 136-150). Teresina: EDUFPI.

Instituto Federal de Educação, Ciência e Tecnologia do Piauí. (2014). Plano de Desenvolvimento Institucional 2015-2019. Teresina: IFPI.

Jorge, J. P. (2017). Psicologia escolar e educação profissional e tecnológica: uma prática em construção. In Negreiros, F.; Souza, M. P. R. (Eds.), Práticas em psicologia escolar: do ensino técnico ao superior (pp. 35-52). Teresina: EDUFPI.

Lima, E. S.; Silva, F. N.; Silva, L. L. S. (2015). Educação profissional para os jovens nas políticas educacionais da 1 a década do século XXI. Holos, 4(31), 119-129. doi: 10.15628/ 
holos.2015.3185

Lukács, G. (1967). Estetica I: La peculiaridade de lo estético. Ediciones Grijalbo, S. A..

Lukács, G. (1970). Introdução a uma estética marxista. Rio de Janeiro: Civilização Brasileira.

Martínez, A. M. (2009). Psicologia Escolar e Educacional: compromissos com a educação brasileira. Psicologia Escolar e Educacional, 13 (1), 169-177. Recuperado de http://pepsic.bvsalud.org/scielo.php?script=sci_ arttext\&pid=S1413-85572009000100020\&lng=pt\&tlng=pt.

Meira, M. E. M. (1997). Psicologia Escolar: pensamento crítico e práticas profissionais (Tese de Doutorado). Universidade de São Paulo, São Paulo, SP, Brasil.

Meira, M. E. M. (2014). Psicologia histórico-cultural: fundamentos, pressupostos e articulações com a Psicologia da educação. In Meira, M. E. M.; Facci, M. G. D. (Eds.), Psicologia histórico-cultural: contribuições para o encontro entre a subjetividade e a educação (pp. 27-62). São Paulo: Casa do Psicólogo.

Oliveira-Menegotto, L. M.; Fontoura, G. P. (2015). Escola e Psicologia: Uma História de Encontros e Desencontros. Psicologia Escolar e Educacional, 19 (2), 377-385. doi: http://dx.doi.org/10.1590/2175-3539/2015/0192869

Patto, M. H. S. (1981). Introdução à Psicologia Escolar. São Paulo: T.A. Queiroz.

Patto, M. H. S. (1987). Psicologia e ideologia: uma introdução crítica à psicologia escolar. São Paulo: T. A. Queiroz.

Patto, M. H. S. (1990). A produção do fracasso escolar: histórias de submissão e rebeldia. (3. ed.). São Paulo: T.A. Queiroz.

Santana, A. C.; Pereira, A. B. M.; Rodrigues, L. G. (2014). Psicologia escolar e Educação Superior: possibilidades de atuação profissional. Psicologia Escolar e Educacional, 18 (2), 229-237.

Santos, A. S.; Souto, D. C.; Silveira, K. S. S.; Perrone, C. M.; Dias,
A. C. G. (2015). Atuação do Psicólogo Escolar e Educacional no ensino superior: reflexões sobre práticas. Psicologia Escolar e Educacional, 19 (3), 515-524. doi: http://dx.doi. org/10.1590/2175-3539/2015/0193888

Sommer, L. C. O.; Bordas, M. A. G. (2018). Inflexões nas atribuições do psicólogo nos Institutos Federais: reflexões, desafios e possibilidades acerca da experiência do psicólogo escolar no IFBA. In Negreiros, F.; Souza, M. P. R. (Eds.), Práticas em psicologia escolar: do ensino técnico ao superior (Vol. 07, pp. 15-38). Teresina: EDUFPI.

Souza, M. P. R. (2010). Psicologia escolar e políticas públicas em Educação: desafios contemporâneos. Em aberto, 23 (83), 129-149.

Souza, M. P. R. (2017). A psicologia escolar brasileira em uma perspectiva crítica e a psicologia histórico-cultural. In Beatón, G. A., Calejon, M. C.; Elejalde, M. F. (Eds.), Enfoque histórico cultural: problemas de las prácticas profesionales (Vol. 2, pp. 11-31). São Paulo: Terracota Editora.

Tanamachi, E. R. (1997). Visão crítica de Educação e de Psicologia: elementos para a construção de uma visão crítica de Psicologia Escolar (Tese de Doutorado). Universidade Estadual Paulista Júlio de Mesquita Filho, Presidente Prudente, SP, Brasil.

Tanamachi, E. R.; Meira, M. E. M. (2003). A atuação do psicólogo como expressão do pensamento crítico em Psicologia e Educação. In Meira, M. E. M.; Antunes, M. A. M. (Eds.), Psicologia escolar: práticas críticas (pp.11-62). São Paulo: Casa do Psicólogo.

Vigotsky, L. S. (2000). A construção do pensamento e da linguagem. São Paulo: Martins Fontes. Traduzido por Paulo Bezerra, do original em russo Michliênie I Rietch. (Obra original publicada em 1934).

Yamamoto, K.; Santos, A. A. L.; Galafassi, C.; Pasqualini, M. G.; Souza, M. P. R. (2013). Como atuam psicólogos na educação paulista? Um estudo sobre suas práticas e concepções. Psicologia: Ciência e Profissão, 33 (4), 794-807. doi: 10.1590/S1414-98932013000400003

Recebido: 01 de maio de 2019 Aprovado: 02 de novembro de 2020 